\title{
ON A QUASISTABILITY RADIUS FOR MULTICRITERIA INTEGER LINEAR PROGRAMMING PROBLEM OF FINDING EXTREMUM SOLUTIONS
}

\begin{abstract}
We consider a multicriteria integer linear programming problem with a targeting set of optimal solutions given by the set of all individual criterion minimizers (extrema). In this study, the lower and upper attainable bounds on the quasistability radius of the set of extremum solutions are obtained when solution and criterion spaces are endowed with different Hölder's norms. As a corollary, an analytical formula for the quasistability radius is obtained for the case where criterion space is endowed with Chebyshev's norm. Some computational challenges are also discussed.
\end{abstract}

Keywords: integer linear programming, multicriteria optimization, extremum solutions, Pareto optimality, stability analysis, quasistability radius, Hölder's norms, Chebyshev's norm.

\section{INTRODUCTION}

While solving practical optimization problems, it is necessary to take into account various kinds of uncertainty due to lack of input data, inadequacy of mathematical models to real processes, rounding off, calculating errors etc. It is known that in many cases initial data as a link between model and reality cannot be defined explicitly. The initial data are defined with a certain error, generally depend on many parameters and require to be specified during the problem solving process. In practice any problem could not be properly posed and solved without at least implicit use of the results of stability analysis and related issues of parametric analysis.

The terms "sensitivity", "stability" or "post-optimal analysis" are generally used for the phase of an algorithm at which a solution (or solutions) of the problem has been already found, and additional calculations are performed in order to investigate how this solution depends on changes in the problem data. Recognition of the stability problem as one of the central in mathematical research goes back to Jacques Hadamard. In 1923, he postulated that in order to be well-posed a problem should have three properties: existence of a solution; uniqueness of the solution; continuous dependence of the solution on the data [1]. Correspondingly, ill-posed multicriteria discrete optimization problem refers to this situation that it may have multiple solutions or the feasible solution set and/or criteria functions depend on uncertain parameters.

Widespread use of discrete optimization models in the last decades stimulated many experts to investigate different aspects of stability of scalar and vector optimization problems. As a consequence, in the context of the operation research and mathematical optimization, the most closely related lines of research have been initiated.

Despite existence of numerous approaches to stability analysis of optimization problems, two major directions can be pointed out: quantitative and qualitative.

A qualitative sensitivity analysis is usually conducted for multicriteria optimization problems with various (linear and nonlinear) partial criteria. The main typical results in there are necessary and sufficient condition formulations for different types of stability of one or a set of optimal solutions in the problems considered (see e.g. [2-11]).

Within the framework of quantitative direction various measures of solution stability are investigated. Analytical expressions, or (attainable) lower and upper bounds, on a quantitative characteristic, called stability radius, usually constitute typical results

(C) V. Emelichev, Yu. Nikulin, 2019 
of the area. The results are usually formulated for the some generalized optimality situation invariant to changes of problem parameters in the case where parameter space is equipped with various metrics (see e.g. [12-20]). In addition to stability radius, some papers are focusing on more general characteristics of stability, for example stability and accuracy functions are analyzed in [21, 22]. Sensitivity analysis is also done for some problem of scheduling theory, see e.g. [23, 24].

This paper belongs to the family of quantitative approaches. It continues a series of publications [10, 14-16, 25-27] seeking for analytical bounds on stability radius (different types of stability) for multicriteria problem of Integer Linear Programming (ILP) with Pareto optimality principle.

In multicriteria optimization and decision making, we deal sometimes with choice functions distinct from the well-known Pareto optimality principle. Such functions have a specific merit in many real life applications (see e.g. [28-32]). In this paper, we consider the multicriteria problem of ILP with extremum optimality principle, i.e. with the set of all extremum solutions. We study the type of stability to independent perturbations of linear function coefficients that is a discrete analogue of Hausdorff semi-continuity mapping transforming any set of problem parameters into a set of extremum solutions. In other words, this type of stability guarantees the existence of a neighborhood in problem parameter space such that none of the solutions disappear within. Following terminology used in [14-17], the type of stability as described above is called quasistability. As a result of parametric analysis, the lower and upper bounds on the quasistability radius are obtained for multicriteria ILP problem with extremum solutions for the case where criterion space is endowed with various Hölder's norms. Attainability of the estimates (both lower and uppers bounds) is shown. As a corollary, we deduce a known before criterion on quasistability of multicriteria ILP problem for the case where criterion space is endowed with Chebyshev's norm.

\section{PROBLEM FORMULATION, BASIC DEFINITIONS AND NOTATION}

We consider an $m$-criteria problem of ILP problem in the following formulation. Let $C=\left[c_{i j}\right] \in \boldsymbol{R}^{m \times n}$ be a real valued $m \times n$-matrix with corresponding rows $C_{i} \in \boldsymbol{R}^{n}, i \in N_{m}=\{1,2, \ldots, m\}, m \geq 1$. Let also $X \subset \boldsymbol{Z}^{n}, 1<|X|<\infty$, be a set of feasible solutions, i.e. a set of integer vectors $x=\left(x_{1}, x_{2}, \ldots, x_{n}\right)^{\mathrm{T}}, n \geq 2$. We define a vector criterion

$$
C x=\left(C_{1} x, C_{2} x, \ldots, C_{m} x\right)^{\mathrm{T}} \rightarrow \min _{x \in X},
$$

with partial criteria being linear functions.

In this paper, $Z^{m}(C), C \in \boldsymbol{R}^{m \times n}$, is a problem of finding the set of extremum solutions defined in traditional way (see e.g. $[29,30]$ ):

$$
E^{m}(C)=\left\{x \in X: \exists k \in N_{m} \forall x^{\prime} \in X\left(C_{k}(x) \leq C_{k}\left(x^{\prime}\right)\right)\right\} .
$$

Thus, the choice of extremum solutions can be interpreted as finding best solutions for each of $m$ criteria, and then combining them into one set. In other words, the set of extremum solutions contains all the individual minimizers of each objective. Obviously, $E^{1}(C), C \in \boldsymbol{R}^{n}$, is the set of optimal solutions for scalar problem $Z^{1}(C)$.

Taking into account that $X$ is finite, the following formulae below are true for any $C \in \boldsymbol{R}^{m \times n}$ :

$$
\begin{gathered}
E^{m}(C)=S l^{m}(C) \backslash\left(P^{m}(C) \backslash L^{m}(C)\right)=L^{m}(C) \cup\left(S l^{m}(C) \backslash P^{m}(C)\right), \\
E^{m}(C) \cap P^{m}(C)=L^{m}(C) \neq \varnothing,
\end{gathered}
$$




$$
\begin{aligned}
& L^{m}(C) \subseteq P^{m}(C) \subseteq S l^{m}(C), \\
& L^{m}(C) \subseteq E^{m}(C) \subseteq S l^{m}(C),
\end{aligned}
$$

where $P^{m}(C)$ denotes the Pareto set [33], $S l^{m}(C)$ denotes the Slater set [34], and $L^{m}(C)$ denotes the lexicographic set (see e.g. $[28,35-37]$ ). Below we define all the three sets in a traditional way:

$$
\begin{gathered}
P^{m}(C)=\left\{x \in X: \nexists x^{0} \in X\left(C x \geq C x^{0} \& C x \neq C x^{0}\right)\right\}, \\
S l^{m}(C)=\left\{x \in X: \nexists x^{0} \in X \forall k \in N_{m}\left(C_{k}(x)>C_{k}\left(x^{0}\right)\right)\right\}, \\
L^{m}(C)=\bigcup_{s \in \Pi_{m}} L(C, s), L(C, s)=\left\{x \in X: \forall x^{\prime} \in X\left(C \leq_{s} C x^{\prime}\right)\right\} .
\end{gathered}
$$

Here $\Pi_{m}$ is the set of all $m$ ! permutations of numbers $1,2, \ldots, m ; s=\left(s_{1}, s_{2}, \ldots\right.$ $\left.\ldots, s_{m}\right) \in \Pi_{m}$; and the binary relation of lexicographic order between two vectors $y=\left(y_{1}, y_{2}, \ldots, y_{m}\right) \in \boldsymbol{R}^{m}$ and $y^{\prime}=\left(y_{1}^{\prime}, y_{2}^{\prime}, \ldots, y_{m}^{\prime}\right) \in \boldsymbol{R}^{m}$ is defined as follows

$$
y \leq_{s} y^{\prime} \Leftrightarrow\left(y=y^{\prime}\right) \vee\left(\exists k \in N_{m} \forall i \in N_{k-1}\left(y_{s_{k}}<y_{s_{k}}^{\prime} \& y_{s_{i}}=y_{s_{i}}^{\prime}\right)\right),
$$

where $N_{0}=\varnothing$. Obviously all the sets, $P^{m}(C), S l^{m}(C), L^{m}(C)$ and $E^{m}(C)$, are non-empty for any matrix $C \in \boldsymbol{R}^{m \times n}$ due to the finite number of alternatives in $X$.

We perturb the elements of matrix $C \in \boldsymbol{R}^{m \times n}$ by adding elements of the perturbing matrix $C^{\prime} \in \boldsymbol{R}^{m \times n}$. Thus the perturbed problem $Z^{m}\left(C+C^{\prime}\right)$ of finding extremum solutions has the following form

$$
\left(C+C^{\prime}\right) x \rightarrow \min _{x \in X}
$$

The set of extremum solutions of the perturbed problem is denoted by $E^{m}\left(C+C^{\prime}\right)$. In the solution space $\boldsymbol{R}^{n}$, we define an arbitrary Hölder's (also known as Minkowski's ) norm $l_{p}, p \in[1, \infty]$, i.e. the norm of vector $a=\left(a_{1}, a_{2}, \ldots, a_{n}\right)^{\mathrm{T}} \in \boldsymbol{R}^{n}$ is defined by the number

$$
\|a\|_{p}= \begin{cases}\left(\sum_{j \in N_{n}}\left|a_{j}\right|^{p}\right)^{1 / p} & \text { if } 1 \leq p<\infty, \\ \max \left\{\left|a_{j}\right|: j \in N_{n}\right\} & \text { if } p=\infty .\end{cases}
$$

The class of $l_{p}$-norms generalizes additive (Manhattan or $l_{1}$ ), the Euclidean $\left(l_{2}\right)$ and $l_{\infty}$ (or $l_{\max }$, also known as Chebyshev's) norms and has a number of applications in various parts of mathematics, physics, and computer science. In the criterion space $\boldsymbol{R}^{m}$, we define another Hölder's norm $l_{q}, q \in[1, \infty]$. The norm of matrix $C \in \boldsymbol{R}^{m \times n}$ is defined by the number

$$
\|C\|_{p q}=\left\|\left(\left\|C_{1}\right\|_{p},\left\|C_{2}\right\|_{p}, \ldots,\left\|C_{m}\right\|_{p}\right)\right\|_{q} .
$$

It is well-known that $l_{p}$ norm, defined in $\boldsymbol{R}^{n}$, induces conjugated $l_{p^{*}}$ norm in $\left(\boldsymbol{R}^{n}\right)^{*}$. For $p$ and $p^{*}$, the following relations hold

$$
\frac{1}{p}+\frac{1}{p^{*}}=1,1<p<\infty .
$$

In addition, if $p=1$, then $p^{*}=\infty$. Obviously, if $p^{*}=1$, then $p=\infty$. Also notice that $p$ and $p^{*}$ belong to the same range $[1, \infty]$. We also set $\frac{1}{p}=0$ if $p=\infty$. 
It is easy to see that for any vector $a=\left(a_{1}, a_{2}, \ldots, a_{n}\right) \in \boldsymbol{R}^{n}$ with $\left|a_{j}\right|=\sigma$, $j \in N_{n}$, it holds

$$
\|a\|_{p}=\sigma n^{1 / p}
$$

for any $p \in[1, \infty]$. For any two vectors $a$ and $b$ of the same dimension, the following Hölder's inequalities are well-known

$$
\left|a^{\mathrm{T}} b\right| \leq\|a\|_{p}\|b\|_{p^{*}}
$$

Using the well-known condition (see [38]) that transforms (2) into equality, the validity of the following statement becomes transparent

$$
\forall b \in \boldsymbol{R}^{n} \forall \sigma>0 \exists a \in \boldsymbol{R}^{n}\left(\left|a^{\mathrm{T}} b\right|=\sigma\|b\|_{p^{*}} \&\|a\|_{p}=\sigma\right) .
$$

Given $\varepsilon>0$, let

$$
\Omega_{p q}(\varepsilon)=\left\{C^{\prime} \in \boldsymbol{R}^{m \times n}:\left\|C^{\prime}\right\|_{p q}<\varepsilon\right\}
$$

be the set of perturbing matrices $C^{\prime}$ with rows $C_{k}^{\prime} \in \boldsymbol{R}^{n}, k \in N_{m}$, and $\left\|C_{p q}^{\prime}\right\|$ is the norm of $C^{\prime}=\left[c_{i j}^{\prime}\right] \in \boldsymbol{R}^{m \times n}$.

Denote

$$
\Theta_{p q}=\left\{\varepsilon>0: \forall C^{\prime} \in \Omega \text { pq }(\varepsilon)\left(E^{m}(C) \subseteq E^{m}\left(C+C^{\prime}\right)\right)\right\} .
$$

Following [14-16, 25], the number

$$
\rho^{m}(p, q)= \begin{cases}\sup \Theta_{p q} & \text { if } \Theta_{p q} \neq \varnothing, \\ 0 & \text { if } \Theta_{p q}=\varnothing,\end{cases}
$$

is called quasistability radius $\left(T_{4}\right.$-stability radius in terminology $\left.[2,4-7,10]\right)$ of problem $Z^{m}(C), m \in \mathbf{N}$, with Hölder's norms $l_{p}$ and $l_{q}$ in the spaces $\boldsymbol{R}^{n}$ and $\boldsymbol{R}^{m}$ respectively. Thus, the quasistability radius of problem $Z^{m}(C)$ defines the extreme level of independent perturbations of the elements of matrix $C$ in the metric space $\boldsymbol{R}^{m \times n}$ preserving all the extremum solutions of $Z^{m}(C)$.

The same concept of quasistability radius of $Z^{m}(C)$ can also be introduced using the definition of the stability kernel, known earlier in [2]. Indeed, it is easy to see that

where

$$
\rho^{m}(p, q)=\sup \left\{\varepsilon>0: \operatorname{Ker}^{m}(C, \varepsilon)=E^{m}(C)\right\},
$$

$$
\operatorname{Ker}^{m}(C, \varepsilon)=\left\{x \in E^{m}(C): \forall C^{\prime} \in \Omega_{p q}(\varepsilon)\left(x \in E^{m}\left(C+C^{\prime}\right)\right)\right\}
$$

is a stability kernel of $Z^{m}(C)$. Thus, the problem $Z^{m}(C)$ is quasistable $\left(\rho^{m}(p, q)>0\right)$ if and only if the stability kernel coincides with the set of original extremum solutions.

\section{BOUNDS ON QUASISTABILITY RADIUS}

Given the multicriteria ILP problem $Z^{m}(C), m \in \boldsymbol{N}$, for any $p \in[1, \infty]$ we set

$$
\phi^{m}(p)=\min _{x^{\prime} \in E^{m}(C)} \max _{i \in N_{m}} \min _{x \in X \backslash\left\{x^{\prime}\right\}} \frac{\left[C_{i}\left(x-x^{\prime}\right)\right]^{+}}{\left\|x-x^{\prime}\right\|_{p^{*}}},
$$

where $[a]^{+}=\max \{0, a\}$ is a nonnegative projection of $a \in \boldsymbol{R}$. Obviously, we have $\phi^{m}(p) \geq 0$. 
Theorem 1. Given $p, q \in[1, \infty]$ and $m \in N$, for the quasistability radius $\rho^{m}(p, q)$ of multicriteria ILP problem $Z^{m}(C)$, the following lower and upper bounds are valid

$$
\phi^{m}(p) \leq \rho^{m}(p, q) \leq \phi^{m}(p) m^{1 / q} .
$$

Proof. First, we prove that $\rho^{m}(p, q) \geq \phi:=\phi^{m}(p)$. If $\phi=0$, then it is evident. Let $\phi>0$. Then according to the definition of $\phi$, the following formula holds

$$
\forall x^{\prime} \in E^{m}(C) \exists k \in N_{m} \quad \forall x \in X \backslash\left\{x^{\prime}\right\}\left(\left[C_{k}\left(x-x^{\prime}\right)\right]^{+} \geq \phi\left\|x-x^{\prime}\right\|_{p^{*}}\right) .
$$

Since $\phi>0$, we have $C_{k}\left(x-x^{\prime}\right)>0$ for $x \neq x^{\prime}$. Assuming $C^{\prime} \in \Omega_{p q}(\phi)$ and taking into account

$$
\left\|C_{k}^{\prime}\right\|_{p} \leq\left\|C^{\prime}\right\|_{p q}<\phi
$$

and Hölder's inequalities (2), we deduce

$$
\begin{gathered}
\left(C_{k}+C_{k}^{\prime}\right)\left(x-x^{\prime}\right)=\left[C_{k}\left(x-x^{\prime}\right)\right]^{+}+C_{k}^{\prime}\left(x-x^{\prime}\right) \geq \\
\geq\left(\phi-\left\|C_{k}^{\prime}\right\|_{p}\right)\left\|x-x^{\prime}\right\|_{p^{*}}>0
\end{gathered}
$$

for any $x \neq x^{\prime}$ i.e. $x^{\prime} \in E^{m}\left(C+C^{\prime}\right)$ for $C^{\prime} \in \Omega_{p q}(\phi)$, and hence we obtain $\rho^{m}(p, q) \geq \phi$.

Further, we prove that $\rho^{m}(p, q) \leq \phi m^{1 / q}$. According to the definition of number $\phi$, we have

$$
\exists x^{0} \in E^{m}(C) \forall i \in N_{m} \quad \forall x(i) \in X\left\{x^{0}\right\}\left(\left[C_{i}\left(x(i)-x^{0}\right)\right]^{+} \leq \phi\left\|x(i)-x^{0}\right\|_{p^{*}}\right) .
$$

Setting $\sigma$ with a condition

$$
\frac{\varepsilon}{m^{1 / q}}>\sigma>\phi
$$

according to formula (3) for any index $i \in N_{m}$ there exists $C_{i}^{0} \in \boldsymbol{R}^{n}$ such that

$$
\begin{gathered}
C_{i}^{0}\left(x(i)-x^{0}\right)=-\sigma\left\|x(i)-x^{0}\right\|_{p^{*}}, \\
\left\|C_{i}^{0}\right\|_{p}=\sigma .
\end{gathered}
$$

Therefore, due to (1), the norm of matrix $C^{0}$ containing rows $C_{i}^{0}, i \in N_{m}$, is calculated as $\left\|C^{0}\right\|_{p q}=\sigma m^{1 / q}$, i.e. $C^{0} \in \Omega$ pq $(\varepsilon)$. Using sequentially (6), (4) and (5) we get for any index $i \in N_{m}$ we deduce

$$
\begin{gathered}
\left(C_{i}+C_{i}^{0}\right)\left(x(i)-x^{0}\right)=C_{i}\left(x(i)-x^{0}\right)+C_{i}^{0}\left(x(i)-x^{0}\right) \leq \\
\leq\left[C_{i}\left(x(i)-x^{0}\right)\right]^{+}-\sigma\left\|x(i)-x^{0}\right\|_{p^{*}} \leq(\phi-\sigma)\left\|x(i)-x^{0}\right\|_{p^{*}}<0 .
\end{gathered}
$$

Thus, $x^{0} \notin E^{m}\left(C+C^{0}\right)$. Hence, the following formula is valid

$$
\forall \varepsilon>\phi m^{1 / q} \exists C^{0} \in \Omega_{p q}(\varepsilon)\left(E^{m}(C) \nsubseteq E^{m}\left(C+C^{0}\right)\right),
$$

i.e. $\rho^{m}(p, q) \leq \phi m^{1 / q}$.

The following corollary from Theorem 1 illustrates the attainability of the lower bound for the quasistability radius. 
Corollary 1. If $q=\infty$, then for any $p \in[1, \infty)$ and $m \in N$ for the quasistability radius $\rho^{m}(p, \infty)$ of multicriteria ILP problem $Z^{m}(C)$ the following formula is valid

$$
\rho^{m}(p, \infty)=\phi^{m}(p)=\min _{x^{\prime} \in E^{m}(C)} \max _{i \in N_{m}} \min _{x \in X \backslash\{x\}} \frac{\left[C_{i}\left(x-x^{\prime}\right)\right]^{+}}{\left\|x-x^{\prime}\right\|_{p^{*}}} .
$$

The next Theorem illustrates the attainability of the upper bound for the quasistability radius specified in Theorem 1 .

Theorem 2. Given $p=\infty, q \in[1, \infty]$ and $m \in N$, there exists a class of multicriteria ILP problem problems such that for any $Z^{m}(C)$ belonging to that class the quasistability radius of $Z^{m}(C)$ can be expressed by the following formula

$$
\rho^{m}(\infty, q)=m^{1 / q} \phi^{m}(\infty)=m^{1 / q} \min _{x^{\prime} \in E^{m}(C)} \max _{i \in N_{m}} \min _{x \in X\left\{x^{\prime}\right\}} \frac{\left[C_{i}\left(x-x^{\prime}\right)\right]^{+}}{\left\|x-x^{\prime}\right\|_{1}} .
$$

Proof. According to Theorem 1, in order to prove equation (7), it suffices to specify a class of problems $Z^{m}(C)$ with $\rho^{m}(\infty, q) \geq m^{1 / q} \phi^{m}(\infty)$. Let $X=\left\{x^{1}, x^{2}, \ldots\right.$ $\left.\ldots, x^{n}\right\} \subset \boldsymbol{E}^{n}=\{0,1\}^{n}$, where $n=m+1$, and every solution $x^{j}, j \in N_{n}$, be a unit vector, i.e. a column of identity matrix of size $n \times n$. Let matrix $C=\left[c_{i j}\right] \in \boldsymbol{R}^{m \times n}$ with rows $C_{i} \in \boldsymbol{R}^{n}, i \in N_{m}$, be constructed as follows:

$$
C=\left(\begin{array}{ccccc}
0 & M & \ldots & M & -2 \alpha \\
M & 0 & \ldots & M & -2 \alpha \\
\ldots & \ldots & \ldots & \ldots & \ldots \\
M & M & \ldots & 0 & -2 \alpha
\end{array}\right),
$$

where $M>>\alpha>0$, and $M$ is a number large enough. Then we have

$$
\begin{aligned}
& C x^{1}=(0, M, \ldots, M, M)^{\mathrm{T}} \in \boldsymbol{R}^{m}, \\
& C x^{2}=(M, 0, \ldots, M, M)^{\mathrm{T}} \in \boldsymbol{R}^{m}, \\
& C x^{n-1}=(M, M, \ldots, M, 0)^{\mathrm{T}} \in \boldsymbol{R}^{m}, \\
& C x^{n}=(-2 \alpha,-2 \alpha, \ldots,-2 \alpha,-2 \alpha)^{\mathrm{T}} \in \boldsymbol{R}^{m} .
\end{aligned}
$$

Thus, $x^{n} \in E^{m}(C), x^{j} \notin E^{m}(C), j \in N_{m}$. Moreover, the following equality is evident

$$
\phi^{m}(\infty)=\max _{i \in N_{m}} \min _{j \in N_{m}} \frac{C_{i}\left(x^{j}-x^{n}\right)}{2}=\alpha .
$$

Let $C^{\prime}=\left[c_{i j}^{\prime}\right] \in \Omega_{\infty q}\left(\alpha m^{1 / q}\right)$ be an arbitrary perturbing matrix with rows $C_{1}^{\prime}$, $C_{2}^{\prime}, \ldots, C_{m}^{\prime}$, i.e. $C^{\prime} \in \boldsymbol{R}^{m \times n},\left\|C^{\prime}\right\|_{\infty}<\alpha m^{1 / q}$. Proving by contradiction, it is easy to show that there exists an index $k \in N_{m}$ with ||$C_{k}^{\prime}||<\alpha$. Therefore, $\left|c_{k j}^{\prime}\right|<\alpha$ for any $j \in N_{n}$. So, we deduce

$$
\left(C_{k}+C_{k}^{\prime}\right)\left(x^{k}-x^{n}\right)=2 \alpha+c_{k k}^{\prime}-c_{k n}^{\prime} \geq 2 \alpha-\left|c_{k k}^{\prime}\right|-\left|c_{k n}^{\prime}\right|>0,
$$

and hence for any index $i \in N_{m} \backslash\{k\}$ we obtain

$$
\left(C_{i}+C_{i}^{\prime}\right)\left(x^{k}-x^{n}\right)=C_{i}\left(x^{k}-x^{n}\right)+C_{i}^{\prime}\left(x^{k}-x^{n}\right)=M+2 \alpha+c_{i k}^{\prime}-c_{i n}^{\prime}>0 .
$$


As a result, we conclude that $x^{n} \in E^{m}\left(C+C^{\prime}\right)$ for any perturbing matrix $C^{\prime} \in \Omega_{\infty q}\left(\alpha m^{1 / q}\right)$ the following inequality holds

$$
\rho^{m}(\infty, q) \geq m^{1 / q} \phi^{m}(\infty),
$$

and hence, taking into account Theorem 1, we get that equality (7) is true, i.e. Theorem 2 is now proven.

The problem $Z^{m}(C)$ is called quasistable if $\rho^{m}(p, q)>0$. We introduce a set of strict extremum solutions of $Z^{m}(C)$ :

$$
S E^{m}(C)=\left\{x \in X: \exists k \in N_{m} \forall x^{\prime} \in X \backslash\{x\}\left(C_{k}(x)<C_{k}\left(x^{\prime}\right)\right)\right\} .
$$

From Theorem 1 we get the following result.

Corollary 2. Given the multicriteria ILP problem $Z^{m}(C)$, the following statements are equivalent

- the problem $Z^{m}(C)$ is quasistable;

- $E^{m}(C)=S E^{m}(C)=\operatorname{Ker}^{m}(C)$;

- $\phi^{m}(p)>0$.

In particular case $m=1$, the scalar problem $Z^{1}(C), C \in \boldsymbol{R}^{n}$, is quasistable if and only if it has a unique optimal solution.

Due to equivalence of any two norms in a finite dimensional linear space (see e.g. $[39,40])$, the result of Corollary 2 is true for any norms specified in the parameter space $\boldsymbol{R}^{m \times n}$ of the problem $Z^{m}(C)$.

At the end, to compare the result of Theorem 1, we present here a formula for calculating the quasistability radius of multicriteria ILP problem $Z_{P}^{m}(C)$ of finding the set of Pareto optimal solutions $P^{m}(C)$ :

$$
\rho_{P}^{m}(p, q)=\min _{x^{\prime} \in P^{m}(C)} \min _{x \in X \backslash\left\{x^{\prime}\right\}} \frac{\left\|\left[C\left(x-x^{\prime}\right)\right]^{+}\right\|_{q}}{\left\|x-x^{\prime}\right\|_{p^{*}}},
$$

where $[a]^{+}=\left(a_{1}^{+}, a_{2}^{+}, \ldots, a_{m}^{+}\right)^{\mathrm{T}}$ is a nonnegative projection of vector $a=\left(a_{1}, a_{2}, \ldots \ldots, a_{m}\right)^{\mathrm{T}} \in \boldsymbol{R}^{m}$, i.e. $a_{i}^{+}=\max \left\{0, a_{i}\right\}, i \in N_{m}$. This formula is clearly follows from the results of [26].

Let $\operatorname{Sm}^{m}(C)$ denote the Smale set for $Z^{m}(C)$ [41]:

$$
\operatorname{Sm}^{m}(C)=\left\{x \in X: \forall x^{\prime} \in X \backslash\{x\} \exists k \in N_{m}\left(C_{k} x<C_{k} x^{\prime}\right)\right\} .
$$

From (1), we can get the following quasistability criterion, known earlier [2, 4, 14-16].

Theorem 3. The multicriteria ILP problem $Z_{P}^{m}(C)$ of finding the Pareto set $P^{m}(C)$ (the set of trade-off or efficient solutions) is quasistable if and only if

$$
P^{m}(C)=\operatorname{Sm}^{m}(C) \text {. }
$$

\section{CONCLUSIONS}

In this paper, the lower and upper attainable bounds on the quasistability radius of the set of extremum solutions were obtained in the situation where solution and criterion spaces are endowed with various Hölder's norms. As corollaries, an analytical formula for the quasistability radius is specified in the case where criterion space is endowed with Chebyshev's norm. One of the biggest challenges in this area is to construct efficient algorithms to calculate the analytical expressions. To the best of our knowledge there are no many results known in that area, and some 
of those results that have been already known, put more questions than answers. As it was pointed out in [42], calculating exact values is an extremely difficult task in general, so one could concentrates either on finding easy computable classes of problems or developing general metaheuristic approaches.

Estimations of quasistability radius obtained in this paper imply complete enumeration the set of feasible solutions whose cardinality may grow exponentially with $n$. In the case of a single objective function, an approach to calculating the stability radius of an $\varepsilon$-optimal solution to the linear problem of $0-1$ programming in polynomial time was given in [43]. They assumed that the objective function is minimized, the feasible solution set is fixed and a given subset of the objective function coefficients is perturbed. The approach requires that the original single objective optimization problem is polynomially solvable, for example it can be one of the well-known graph theory problems, such as minimum spanning tree or shortest path problems. In [17], it was shown how analytical formulae similar to (8) can be transformed into polynomial type calculation procedure in the case of Boolean variables, Chebyshev norm and polynomial solvability of $Z_{P}^{1}(C)$. However, for multicriteria case the question of existing polynomial time procedures remains to be open. As it is well-known that the presence of multiple criteria increases the level of complexity, for example, polynomially solvable single objective problems become intractable even in bicriteria case, see e.g. [44], the finding of polynomial methods seems to be unlikely in general. For some particular challenging combinatorial problems, it was proven that the problem of finding the radii of every type of stability is intractable unless $P=N P$ [45]. An application of inverse optimization usually results in logarithmic number of mixed integer programs for multi-objective combinatorial problems, where each objective function is a maximum sum and the coefficients are restricted to natural numbers [46].

\section{REFERENCES}

1. Hadamard J. Lectures on Cauchy's problem in linear partial differential equations. New Haven: Yale University Press. 1923. 316 p.

2. Sergienko I., Shilo I. Discrete optimization problems: problems, methods of solution, research. Kyiv: Nauk. dumka, 2003. 264 p. (In Russian).

3. Belousov E., Andronov V. Solvability and Stability for Problems of Polynomial Programming. Moscow: Moscow University Publisher, 1993.

4. Sergienko I., Kozeratskaya L., T. Lebedeva: Stability and Parametric analysis of discrete optimization problems. Kyiv: Nauk. dumka, 1995. 168 p. (In Russian).

5. Lebedeva T., Semenova N., Sergienko T. Stability of vector problems of integer optimization: relationship with the stability of sets of optimal and nonoptimal solutions. Cybernetics and Systems Analysis. 2005. Vol. 41, N 4. P. 551-558.

6. Lebedeva T., Sergienko T. Stability of a vector integer quadratic programming problem with respect to vector criterion and constraints. Cybernetics and Systems Analysis. 2006. Vol. 42, N 5. P. 667-674.

7. Lebedeva T., Sergienko T. Different types of stability of vector integer optimization problem: general approach. Cybernetics and Systems Analysis. 2008. Vol. 44, N 3. P. 429-433.

8. Lebedeva T., Semenova N., Sergienko T. Qualitative characteristics of the stability of vector discrete optimization problems with different optimality principles. Cybernetics and Systems Analysis. 2014. Vol. 50, N 2. P. 228-233.

9. Lebedeva T., Semenova N., Sergienko T. Properties of perturbed cones ordering the set of feasible solutions of vector optimization problem. Cybernetics and Systems Analysis. 2014. Vol. 50, N 5. P. $712-717$.

10. Emelichev V., Kotov V., Kuzmin K., Lebedeva T., Semenova N., Sergienko T. Stability and effective algorithms for solving multiobjective discrete optimization problems with incomplete information. Journal of Automation and Information Sciences. 2014. Vol. 46, Iss. 2. P. 27-41. 
11. Kuzmin K., Nikulin Y., Mäkelä M. On necessary and sufficient conditions of stability and quasistability in combinatorial multicriteria optimization. Control and Cybernetics. 2017. Vol. 46, N 4. P. 361-382.

12. Leontev V. Discrete optimization. Journal of Computational Physics and Mathematics. 2007. Vol. 47, Iss. 2. P. 328-340.

13. Gordeev E. Comparison of three approaches to studying stability of solutions to problems of discrete optimization and computational geometry. Journal of Applied and Industrial Mathematics. 2015. Vol. 9, Iss. 3. P. 358-366.

14. Emelichev V., Podkopaev D. On a quantitative measure of stability for a vector problem in integer programming. Journal of Computational Physics and Mathematics. 1998 Vol. 38, Iss. 11. P. 1727-1731.

15. Emelichev V., Podkopaev D. Stability and regularization of vector problems of integer linear programming. Diskretnyi Analiz i Issledovanie Operatsii. Ser. 2. 2001. Vol. 8, N 1. P. 47-69.

16. Emelichev V., Girlich E., Nikulin Y., Podkopaev D. Stability and regularization of vector problems of integer linear programming. Optimization. 2002. Vol. 51, N 4. P. 645-676.

17. Emelichev V., Podkopaev D. Quantitative stability analysis for vector problems of 0-1 programming. Discrete Optimization. 2010. Vol. 7, Iss. 1-2. P. 48-63.

18. Emelichev V., Kuzmin K. Stability radius of a vector integer linear programming problem: case of a regular norm in the space of criteria. Cybernetics and Systems Analysis. 2010. Vol. 46, N 1. P. $72-79$.

19. Emelichev V., Korotkov V. Stability radius of a vector investment problem with Savage's minimax risk criteria. Cybernetics and Systems Analysis. 2012. Vol. 48, N 3. P. 378-386.

20. Bukhtoyarov S., Emelichev V. On the stability measure of solutions to a vector version of an investment problem. Journal of Applied and Industrial Mathematics. 2015. Vol. 9, Iss. 3. P. $328-334$.

21. Libura M., Nikulin Y. Stability and accuracy functions in multicriteria linear combinatorial optimization problem. Annals of Operations Research. 2006. Vol. 147, Iss. 1. P. 255-267.

22. Nikulin Y. Stability and accuracy functions in a coalition game with bans, linear payoffs and antagonistic strategies. Annals of Operations Research. 2009. Vol. 172, N 1. P. 25-35.

23. Sotskov Y., Sotskova N., Lai T., Werner F. Scheduling under uncertainty, theory and algorithms. Minsk: Belaruskaya nauka, 2010. 328 p.

24. Nikulin Y. Accuracy and stability functions for a problem of minimization a linear form on a set of substitutions. In: Sequencing and Scheduling with Inaccurate Data. Sotskov Y. and Werner F. (Eds). Nova Science Pub Inc., 2014. Ch. 15. P. 409-426.

25. Emelichev V., Platonov A. Measure of quasistability of a vector integer linear programming with generalized principle of optimality in the Hölder metric. Buletine of Academy of Sciences of Moldova. Mathematics. 2008. Vol. 57(2). P. 58-67.

26. Emelichev V., Kuzmin K. A general approach to studying the stability of a Pareto optimal solution of a vector integer linear programming problem. Discrete Mathematics and Applications. 2007. Vol. 17, Iss. 4. P. 349-354.

27. Emelichev V., Kuzmin K. On a type of stability of a multicriteria integer linear programming problem in the case of monotonic norm. Journal of Computers and Systems Sciences International. 2007. Vol. 46, N 5. P. 714-720.

28. Podinovskii V., Noghin V. Pareto-optimal solutions of multicriteria problems. Moscow: Fizmatlit, 2007. 256 p.

29. Sholomov L. Logical methods for investigation of the discrete choice models. Moscow: Nauka, 1989. 288 p.

30. Yudin D. Computational methods in decision making. Moscow: Nauka, 1989. 320 p.

31. Aizerman M., Aleskerov F. Choice of alternatives: theoretical foundations. Moscow: Nauka, 1990.

32. Lotov A., Pospelova I. Multicriteria decision making problems. Moscow: MAKS Press, 2008. 197 p.

33. Pareto V. Manuel D'ecoonomie Politique. Paris: V. Giard \& E. Brière, 1909. 695 p.

34. Slater M. Lagrange multipliers revisited. cowles commission discussion Paper 80. Mathematics 1950; In: Traces and Emergence of Nonlinear Programming. Giorgi G. and Kjeldsen T. (Eds.). Basel: Birkhäuser, 2014. P. 293-306.

35. Steuer R.E. Multiple criteria optimization: theory, computation and application. New York: John Wiley \&Sons, 1986. 546 p.

36. Miettinen K. Nonlinear multiobjective optimization. Boston: Kluwer Academic Publishers, 1999. 293 p.

37. Noghin V. Reduction of the Pareto set: an axiomatic approach (studies in systems, decision and control). Cham: Springer, 2018. 232 p.

38. Hardy G., Littlewood J., Polya G. Inequalities. Cambridge: Cambridge University Press, 1988. 338 p. 
39. Tikhonov A., Arsenin V. Solutions of ill-posed problems. Washington; Winston; New York: distributed solely by Halsted Press, 1977. 255 p.

40. Kolmogorov A., Fomin S. Elements of the theory of functions and functional analysis. Moscow: Fizmatlit, 2009. 570 p.

41. Smale S. Global analysis and economics V: Pareto theory with constraints. Journal of Mathematical Economics. 1974. Vol. 1, Iss. 3. P. 213-221.

42. Nikulin Y., Karelkina O., Mäkelä M.M. On accuracy, robustness and tolerances in vector Boolean optimization. European Journal of Operational Research. 2013. Vol. 224, Iss. 3. P. 449-457.

43. Chakravarti N., Wagelmans A. Calculation of stability radius for combinatorial optimization problems. Oper. Res. Lett. 1998. Vol. 23, Iss. 1-2. P. 1-7.

44. Ehrgott M. Multicriteria optimization. Berlin; Heidelberg: Springer-Verlag, 2005. 323 p.

45. Kuzmin K. A general approach to the calculation of stability radii for the max-cut problem with multiple criteria. Journal of Applied and Industrial Mathematics. 2015. 9(4). P. 527-539.

46. Roland J., Smet Y., Figueira J. On the calculation of stability radius for multi-objective combinatorial optimization problems by inverse optimization. 4OR-Q. J. Oper. Res. 2102. Vol. 10, Iss. 4. P. 379-389.

Надійшла до редакиії 22.11.2018

\title{
В.О. Смслічев, Ю.В. Нікулін
}

ПРО РАДІУС КВАЗІСТІЙКОСТІ ДЛЯ БАГАТОКРИТЕРІЙНОЇ ЦІЛОЧИСЕЛЬНОЇ ЗАДАЧІ ЛІНІЙНОГО ПРОГРАМУВАННЯ ПРО ЗНАХОДЖЕННЯ ЕКСТРЕМАЛЬНИХ РОЗВ'ЯЗКІВ

Анотація. Розглянуто багатокритерійну задачу цілочисельного лінійного програмування 3 цільовим набором оптимальних розв'язків, кожен 3 яких мінімізує хоча б один 3 критеріїв, тобто $є$ екстремумом. Нижні та верхні досяжні оцінки радіуса квазістійкості множини екстремальних розв'язків доведено у ситуації, коли у просторах розв'язків та критеріїв задані різні норми Гельдера. Як наслідок отримано аналітичну формулу для радіусу квазістійкості у випадку, коли у просторі критеріїв задана норма Чебишова. У роботі також коротко обговорюються деякі питання пов'язані з обчислюванністю.

Ключові слова: цілочисельне лінійне програмування, багатокритерійна оптимізація, екстремальні розв'язки, оптимальність за Парето, аналіз стійкості, радіус квазістійкості, норми Гельдера, норма Чебишова.

\section{В.А. Емеличев, Ю.В. Никулин \\ О РАДИУСЕ КВАЗИУСТОЙЧИВОСТИ МНОГОКРИТЕРИАЛЬНОЙ ЗАДАЧИ ЦЕЛОЧИСЛЕННОГО ЛИНЕЙНОГО ПРОГРАММИРОВАНИЯ НАХОЖДЕНИЯ ЭКСТРЕМАЛЬНЫХ РЕШЕНИЙ}

\begin{abstract}
Аннотация. Рассматривается многокритериальная задача целочисленного линейного программирования с целевым набором оптимальных решений, каждое из которых минимизирует хотя бы один из критериев, т.е. является экстремумом. В данной работе нижние и верхние достижимые оценки радиуса квазиустойчивости множества экстремальных решений доказаны в ситуации, когда в пространствах решений и критериев заданы различные нормы Гёльдера. В качестве следствия получена аналитическая формула радиуса квазиустойчивости для случая, когда в пространстве критериев задана норма Чебышёва. В работе также кратко обсуждены некоторые вопросы, связанные с вычислимостью.
\end{abstract}

Ключевые слова: целочисленное линейное программирование, многокритериальная оптимизация, экстремальные решения, оптимальность по Парето, анализ устойчивости, радиус квазиустойчивости, нормы Гёльдера, норма Чебышёва.

Emelichev Vladimir,

Department of Mathematical Cybernetics, Mechanics and Mathematics Faculty, Belarusian State University, Minsk, Belarus, e-mail: vemelichev@gmail.com.

Nikulin Yury,

Department of Mathematics and Statistics, Faculty of Science and Engineering, University of Turku, Finland, e-mail: yurnik@utu.fi. 